

\title{
Size and Concentration Effects on Surface Plasmon Resonance and Maxwell-Garnett Absorption in RF-Magnetron Sputtered $\mathrm{Au} / \mathrm{Al}_{2} \mathrm{O}_{3}$ Nanocomposite Films
}

\author{
A. Belahmar ${ }^{1}$, A. Chouiyakh ${ }^{2, *}$ \\ Department of Physics, Renewable Energy and Environment Laboratory, Faculty of Science, Ibn Tofail University, B.P.133, 14000 Kenitra, Morocco.
}

\section{ART ICLE DETAILS}

\section{Article history:}

Received 15 March 2017

Accepted 27 May 2017

Available online 01 July 2017

\section{Keywords:}

Au Nanoparticles

Lattice Parameter

$\mathrm{Au}$ Concentration

M-G Theory

\begin{abstract}
A B S T R A C T
$\mathrm{Au} / \mathrm{Al}_{2} \mathrm{O}_{3}$ nanocomposite films, studied in this work, were prepared by $\mathrm{RF}$-magnetron sputtering technique on glass substrate at room temperature under two different argon pressures, and subsequent heat treatment. Formation of gold nanoparticles was confirmed by X-ray diffraction patterns and UVvisible absorption spectroscopy. Au fill fraction $\mathrm{f}$, changed from $\mathrm{f}=10.78 \%$ to $\mathrm{f}=25.45 \%$, when argon pressure increased from $2 \times 10^{-3}$ mbar to $10 \times 10^{-3}$ mbar. For the as-deposited samples, reduction in volume fraction of gold particles causes a decrease in particle size, a lattice expansion and a blue-shift of the SPR peak position. An opposite trend is observed in the lattice parameter with respect to the gold volume fraction for the annealed samples. A small change in the sizes is observed and no significant shift of band absorption peak in samples of low Au content. However, at higher Au concentration, an appreciable red shift of the surface plasmon resonance with increasing temperature is observed. Experimental optical absorption spectra of all the samples were theoretically simulated by MaxwellGarnett effective medium theory.
\end{abstract}

\section{Introduction}

Thin films containing metal nanoparticles (NPs) exhibited a specific physical properties different from those of the corresponding bulk material have been for a long time the subject of various experimental and theoretical studies. One of the main properties of interest is the optical, that when light impinges onto a metallic NP, its free conduction electrons may respond collectively by oscillating in resonance. This collective resonant excitation, which occurs in the visible range of the electromagnetic spectrum in the case of noble metal nanoparticles, is known as a surface plasmon resonance (SPR) [1, 2]. The resonance frequency is influenced by several factors, e.g. size, shape and the chemical environment of the metal NPs, such that modifying one of these parameters represents a way to control the properties of the corresponding composite materials (i.e., a matrix containing metallic NPs) [3-7].

Optical properties, particularly for small gold nanoparticles (Au-NPs), embedded in different dielectric matrices have attracted researchers for their fundamental and various applications [8-21]. To model the optical absorption spectra, various theoretical models have been developed to simulate the optical response of the metal/dielectric nanocomposite films. Among them, as early as 1908, SPR was first quantitatively described by Mie's theory by solving Maxwell's equation with appropriate boundary conditions for spherical particles, and under the assumption that there is no interaction between the metal nanoparticles. However, additional effects related to size and interaction between nanoparticles cannot be ignored in the optical properties. Another significant drawback for this theory arise from the assumption that dielectric constant of small metal nanoparticles is same as bulk, but opposite is true [22, 23].

Indeed, for larger metal volume fractions, the Maxwell-Garnett (M.G) effective medium theory agrees better with the experimental results by introducing the particle-particle interactions, as well as the modifications induced by the matrix material [24]. This theory describes quite well the position and shape of the SPR and its dependence on the metal filling factor [25]. The effective dielectric constant $\varepsilon_{e f f}(\omega)$ of a composite material with spherical metal inclusions having a filling factor $f$ is given by the expression:

$$
\varepsilon_{e f f}(\omega)=\varepsilon_{m} \frac{\left(\varepsilon_{i}(\omega)+2 \varepsilon_{m}\right)+2 f\left(\varepsilon_{i}(\omega)-\varepsilon_{m}\right)}{\left(\varepsilon_{i}(\omega)+2 \varepsilon_{m}\right)-f\left(\varepsilon_{i}(\omega)-\varepsilon_{m}\right)}
$$

where $\varepsilon_{\mathrm{i}}(\omega)$ and $\varepsilon_{\mathrm{m}}$ are the complex dielectric functions of the metal and the host matrix, respectively. The dielectric function of Au was taken from the work of Palik [26]. The dependence of the metal dielectric function on the size of the particles is taken into account using the model presented by Hövel et al [27]:

$$
\varepsilon(\lambda, D)=\varepsilon^{b u l k}(\lambda)+\frac{\omega_{P}^{2}}{\omega^{2}+i \omega \Gamma_{b u l k}}-\frac{\omega_{P}^{2}}{\omega^{2}+i \omega\left(\Gamma_{b u l k}+2 A v_{F} / D\right)}
$$

where $\varepsilon$ is the bulk gold dielectric constant, $\omega_{\mathrm{P}}, \mathrm{v}_{\mathrm{F}}$ and $\Gamma_{\mathrm{bulk}}$ being, the metal plasma frequency, the Fermi velocity and the electron scattering rates in the bulk respectively, and A is a phenomenological parameter including details of the scattering process. The absorption coefficient $\alpha$ of the composite can be obtained from the following formula [28]:

$$
\alpha=\frac{4 \pi}{\lambda \sqrt{2}}\left[\left(\varepsilon_{\mathrm{e} 1}^{2}+\varepsilon_{\mathrm{e} 2}^{2}\right)^{1 / 2}-\varepsilon_{\mathrm{e} 1}\right]^{1 / 2}
$$

where $\varepsilon_{\mathrm{e} 1}$ and $\varepsilon_{\mathrm{e} 2}$ are the real and imaginary parts of the effective dielectric function $\varepsilon_{\text {eff }}$.

Because metal/dielectric nanocomposite films can be elaborated with appropriate properties, synthesized techniques are very important. A variety of methods have been used for synthesizing $\mathrm{Au} / \mathrm{Al}_{2} \mathrm{O}_{3}$ composite films, such as melt quenching, ion implantation [29-31], sol-gel [32, 33], Laser evaporation [34-37], and RF magnetron sputtering [38-43]. The flexibility that permits the fabrication of diverse composite films using various metal-dielectric combinations and the capability to produce composite films with uniformly distributed metal particles are other advantages of sputtering methods $[44,45]$.

As a comparison to the theoretical works, the experimental data in the literature are much scattered and in many cases confusing. Although it has been identified that the SPR is influenced by four factors including the metal particle size, as well as the concentration, shape, and dielectric function of the surrounding materials $[4,46,47]$. The complicated sources of the first two factors make it difficult to differentiate them experimentally. Moreover, the lack of experimental data in the small size regime causes more confusion when compared with various theoretical models.

The present work focuses on the investigation of the influence of $\mathrm{Au}$ concentration and thermal annealing on the structural and optical properties of $\mathrm{Au} / \mathrm{Al}_{2} \mathrm{O}_{3}$ nanocomposite films deposited by RF-magnetron 
sputtering. The as-deposited and heat-treated composite films were examined by X-ray diffraction, EDX and optical absorption spectroscopy.

\section{Experimental Methods}

$\mathrm{Au} / \mathrm{Al}_{2} \mathrm{O}_{3}$ composite thin films were grown by $\mathrm{RF}$ magnetron sputtering technique using an Alcatel SCM 650 system. The target is constituted by two materials: alumina disc (99.99\%) with a diameter of $50 \mathrm{~mm}$, over which chips of gold covering a fraction $\left(\mathrm{r}_{\mathrm{Au} / \mathrm{Al}_{2} \mathrm{O}_{3}}=1.3 \%\right)$, were placed on top of alumina disc. Sputter deposition, in a radio frequency $(13.56 \mathrm{MHz})$ machine, has been carried out after the chamber reached a base pressure of $1 \times 10^{-6} \mathrm{mbar}$, before the argon gas for the sputtering was introduced. In order to obtain desired metal particle size and concentration, the argon pressure deposition was varied. The films has been grown on glass substrates (ISO 8037) at room temperature. The substrate to target distance, deposition time and applied power were fixed at $60 \mathrm{~mm}, 4 \mathrm{~h}$ $30 \mathrm{~min}$ and $50 \mathrm{w}$ respectively. Two set of samples were prepared at room temperature under $2 \times 10^{-3}$ mbar and $10 \times 10^{-3} \mathrm{mbar}$, they are denoted $\mathrm{A} 1$ and $\mathrm{A} 2$ respectively. After deposition, the samples were additionally annealed at temperatures $300{ }^{\circ} \mathrm{C}, 400{ }^{\circ} \mathrm{C}$ and $500{ }^{\circ} \mathrm{C}$ for 1 hour. Structural properties of the composite films were examined by X-ray diffraction (XRD), using a Siemens D5000 diffractometer. The atomic concentration of the $\mathrm{Au}$ was examined by Energy Dispersive X-Ray Analysis (EDX). Finally the optical absorption spectra of the composite films was measured using Shimadzu UV 3101 PC spectrophotometer, in the wavelength range of $200-2000 \mathrm{~nm}$.

\section{Results and Discussion}

\subsection{Structural Characterization}

\subsubsection{Energy-Dispersive X-Ray Spectroscopy (EDX) Analysis}

The EDX analysis of the $\mathrm{Au} / \mathrm{Al}_{2} \mathrm{O}_{3}$ composite films shown in Fig. 1 and Fig. 2, confirms the presence of oxygen (O), aluminum (Al) and gold ( $\mathrm{Au})$. There also exist peaks for $\mathrm{Si}, \mathrm{Na}$ and $\mathrm{Ca}$ due to the glass substrate.



Fig. 1 EDX Spectra of $\mathrm{Au} / \mathrm{Al}_{2} \mathrm{O}_{3}$ composite films deposited at $2 \times 10^{-3} \mathrm{mbar}$

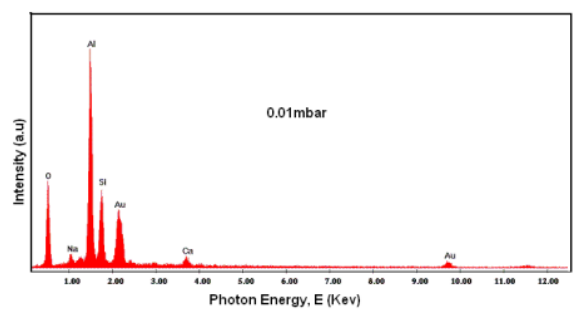

Fig. 2 EDX Spectra of $\mathrm{Au} / \mathrm{Al}_{2} \mathrm{O}_{3}$ composite films deposited at $10 \times 10^{-3} \mathrm{mbar}$

Table 1 Quantitative results of $\mathrm{Au} / \mathrm{Al}_{2} \mathrm{O}_{3}$ thin films from EDX analysis

\begin{tabular}{|c|c|c|c|c|c|}
\hline $\begin{array}{l}\text { Compositions of } \\
\mathrm{Au} / \mathrm{Al}_{2} \mathrm{O}_{3} \text { thin } \\
\text { films }\end{array}$ & $\begin{array}{l}\text { Argon } \\
\text { Pressure } \\
\text { (mbar) }\end{array}$ & Element & Weight $\%$ & Atom $\%$ & $\begin{array}{l}\text { Au filling } \\
\text { factor }(f)\end{array}$ \\
\hline \multirow{3}{*}{ A1 } & \multirow{3}{*}{$2.10^{-3}$} & $\mathrm{Au}$ & 36.41 & 5.47 & \multirow{3}{*}{0.1078} \\
\hline & & $\mathrm{Al}$ & 30.74 & 33.74 & \\
\hline & & 0 & 32.85 & 60.79 & \\
\hline \multirow{3}{*}{$\mathrm{A} 2$} & \multirow{3}{*}{$10.10^{-3}$} & $\mathrm{Au}$ & 62.81 & 14.68 & \multirow{3}{*}{0.2545} \\
\hline & & $\mathrm{Al}$ & 18.49 & 31.53 & \\
\hline & & 0 & 18.70 & 53.80 & \\
\hline
\end{tabular}

The quantitative results of $\mathrm{Au} / \mathrm{Al}_{2} \mathrm{O}_{3}$ thin films reported in Table 1 show, that the atom \% for $\mathrm{Au}$ increases from $5.47 \%$ to $14.68 \%$ when the Argon pressure value changes from $2 \times 10^{-3}$ to $10 \times 10^{-3}$ mbar. The atomic percentage was then converted to the volume concentration (also known as the filling factor) by the formula:

$$
f=\frac{\frac{a t . \% \times \text { molecular mass }}{\text { density }} \text { of } \mathrm{Au}}{\frac{\text { at.\% } \times \text { molecularmass }}{\text { density }} \text { of } \mathrm{Au}+\frac{\text { at. } \% \times \text { molecularmass }}{\text { density }} \text { of } \mathrm{Al}_{2} \mathrm{O}_{3}}
$$

The calculated values of $f$ are $10.78 \%$ and $25.45 \%$ corresponding to $2 \times 10^{-3}$ and $10 \times 10^{-3}$ mbar respectively. So, the Au concentration can be controlled by the magnetron sputtering technique deposition parameters, precisely by working argon pressure in this study.

\subsubsection{Structural Analysis}

In order to investigate the effect of $\mathrm{Au}$ concentration on structural properties of $\mathrm{Au} / \mathrm{Al}_{2} \mathrm{O}_{3}$ nanocomposite films, the XRD measurements were performed. Fig. 3 shows the X-ray diffraction patterns of the samples deposited at two working argon pressure, $2 \times 10^{-3} \mathrm{mabr}$ and $10 \times 10^{-3} \mathrm{mabr}$, implicitly at two concentrations ( $f_{1}=10.78 \%$ and $f_{2}=25.45 \%$ respectively). $\mathrm{X}$-ray diffractogram of gold thin film with a cubic structure, presented as a reference, is also reported in Fig. 3. No reflection peaks are visible from the XRD pattern of the A1 series. With increasing $\mathrm{Au}$ concentration, the broadening peaks with low intensity for the A2 series are most likely due to the small size of the Au-NPs [49]. This make difficult the determination of peak position and full width of half maximum (FWHM) with a good accuracy. So, the XRD patterns were deconvoluted, assuming pseudo-Voigt functions using commercial software program available on our computer. Note that the purpose of the deconvolution is to fit the measured XRD spectrum in well-defined peaks to which a physical meaning can be attributed. For more details see the works [28, 41-43, 48, 49]. The curve fitting XRD spectrum of A1 series is reported in Fig. 4. Outside the peak assigned to amorphous alumina film, the diffraction peaks resulting from the fitting are attributed to the crystal planes of $\mathrm{Au}$ (111), $\mathrm{Au}$ (200) and $\mathrm{Au}$ (220). The peak positions are in agreement with the well-known data: IJPDS-04-0784 characteristic of the FCC cubic structure, indicating that the small gold particles should adopt a fcc-like structure.

On the basis of the peak width, $\beta$ in radians, at a $2 \theta$ value of Bragg's angle of the $\mathrm{Au}(111)$ reflection, the crystallite sizes were estimated from the Debye-Scherrer's equation: $D=k \lambda / \beta \cos \theta_{\beta}$; where $\mathrm{K}$ is a constant taken as 0.9 and $\beta$ is the integral breadth that depends on the width of the particular $h k l$ plane; $\lambda=1.5406 \AA$, is the wavelength of the $\mathrm{CuK}_{\alpha}$ source. The lattice parameter $a$ were determined using the equation $d_{(h k l)}=$ $\mathrm{a} / \sqrt{h^{2}+k^{2}+l^{2}}$, where the value of $d_{(h k l)}$, for an XRD peak was determined from Bragg's law, $2 d_{(h k l)} \sin \theta=n \lambda$. Here, $h k l$ is the crystal plane indices, $d_{(h k l)}$ is the distance between crystal planes of $(h k l)$. The calculated size of Au-NPs increases from $0.84 \mathrm{~nm}$ to $1.25 \mathrm{~nm}$ when the $\mathrm{Au}$ concentration increases from $10.78 \%$ to $25.45 \%$. While the corresponding values of lattice parameter decreases from $4.098 \AA$ to $4.065 \AA$.

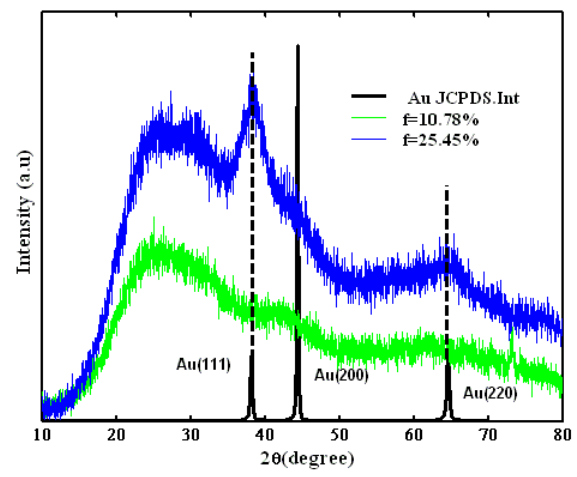

Fig. $3 \mathrm{X}$-ray diffractograms of the two series: $\mathrm{A} 1(\mathrm{f}=10.70 \%)$ and $\mathrm{A} 2(\mathrm{f}=25.45)$ and JCPDS of gold thin films

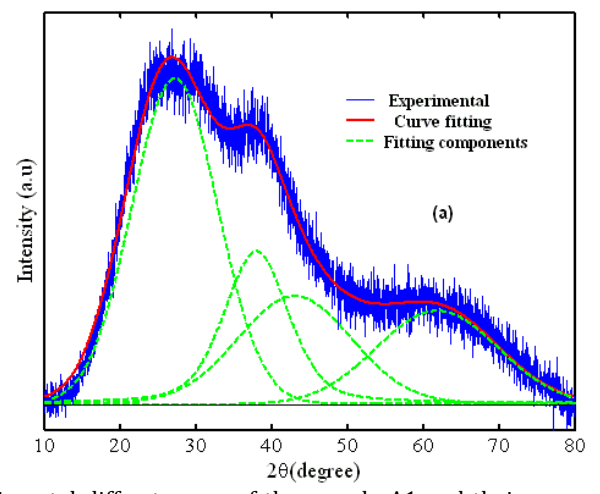

Fig. 4 Experimental diffractogram of the sample A1 and their curve fitting where different pseudo-Voigt functions were taken into account 
In order to promote some structural changes that will be required to tailor the SPR effect, the films were thermally annealed in air, at temperatures ranging from $300^{\circ} \mathrm{C}$ up to $500^{\circ} \mathrm{C}$. For $\mathrm{A} 1$ series, the peak $\mathrm{Au}$ (111) became apparent at $300^{\circ} \mathrm{C}$, according to the results displayed in Fig. 5 . The broad XRD peak seems to become more intense and narrower, which might be an indication of increasing Au nanoclusters formation. After deconvolution, the deduced values of lattice parameter and the estimated size from the Au (111) reflection are reported in Table 2. A shift to higher angles, indicating lattice contraction, was observed. The values of lattice parameter decreases from $4.138 \AA$ to $4.058 \AA$ and the mean diameters of Au-NPs vary from $0.66 \mathrm{~nm}$ to $1.01 \mathrm{~nm}$, when the annealing temperatures vary from $25^{\circ} \mathrm{C}$ to $500^{\circ} \mathrm{C}$. A similar trend is observed for the annealed A2 series in which the Au-NPs size increases from $1.25 \mathrm{~nm}$ to 1.7 $\mathrm{nm}$ as shown in Fig. 6. The lattice parameter presents an opposite trend with annealing temperature. Its show an increase from $4.068 \AA$ to $4.101 \AA$. Variation of lattice parameter with annealing temperature of the two samples is represented in Fig. 7. It is evident from this figure that the annealing treatment has an opposite effect on the two series. For the A2, there is an expansion of the lattice parameter, whereas a contraction has occurred for the A1.

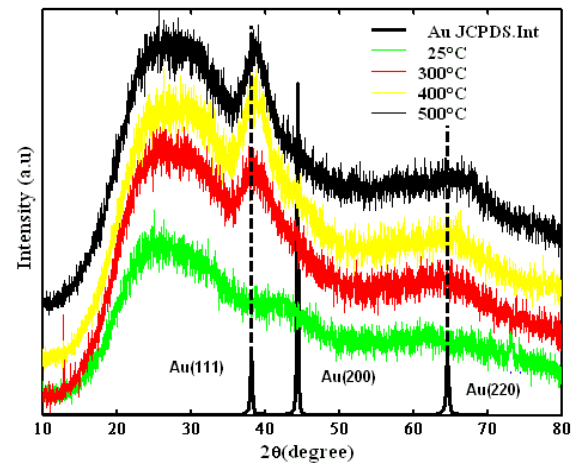

Fig. $5 \mathrm{X}$-ray diffractograms of the sample $\mathrm{A} 1$ as-grown, heated at $300{ }^{\circ} \mathrm{C}, 400{ }^{\circ} \mathrm{C}, 500$ ${ }^{\circ} \mathrm{C}$ and JCPDS of gold thin films

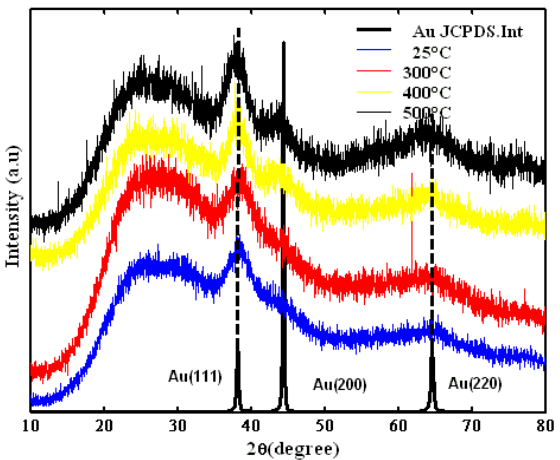

Fig. $6 \mathrm{X}$-ray diffractograms of the sample $\mathrm{A} 2$ as-grown, heated at $300{ }^{\circ} \mathrm{C}, 400{ }^{\circ} \mathrm{C}, 500$ ${ }^{\circ} \mathrm{C}$ and JCPDS of gold thin films

On the basis of the EDX and X-ray diffraction measurements, from the variation of the argon pressure, we can easily control the size and the concentration of $\mathrm{Au}$ in the $\mathrm{Au} / \mathrm{Al}_{2} \mathrm{O}_{3}$ composite films. The results of the influence of gold concentration on the as-deposited thin films can be summarizing in two observations: an increase of particle size and a decrease of lattice constant when the sputtering argon pressure is increased. The thermal annealing favors the formation of Au-NPs with larger size [50].

Table 2 Results of the curve fitting of the experimental diffractograms of the two series A1 and A2 as grown and annealed

\begin{tabular}{llll}
\hline Sapmle number & $\begin{array}{l}\text { Annealing } \\
\text { temperature }\left({ }^{\circ} \mathrm{C}\right)\end{array}$ & $\begin{array}{l}\text { Lattice constant } \\
(\AA)\end{array}$ & $\begin{array}{l}\text { Particle Size } \\
(\mathrm{nm})\end{array}$ \\
\hline & as-prepared & 4.138 & 0.66 \\
$\mathrm{~A} 1$ & $300^{\circ} \mathrm{C}$ & 4.101 & 0.83 \\
& $400^{\circ} \mathrm{C}$ & 4.0795 & 0.93 \\
& $500^{\circ} \mathrm{C}$ & 4.058 & 1.04 \\
\hline & & 4.068 & 1.25 \\
$\mathrm{~A} 2$ & $300^{\circ} \mathrm{C}$ & 4.079 & 1.36 \\
& $400^{\circ} \mathrm{C}$ & 4.084 & 1.39 \\
& $500^{\circ} \mathrm{C}$ & 4.101 & 1.70 \\
\hline
\end{tabular}

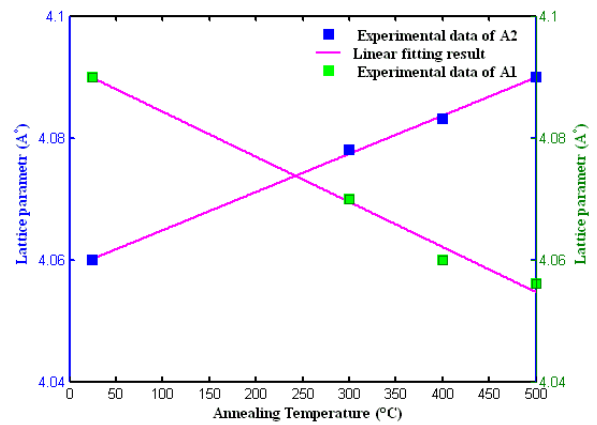

Fig. 7 Variation of lattice parameter of Au-NPs with annealing temperatute

\subsection{Optical characterization}

Based on the M.G theory, the surface-plasmon resonance occurs when

$$
\varepsilon_{1}\left(\omega_{s}\right)(1-f)+\varepsilon_{m}(2-f)=0
$$

where $\omega_{s}$ is the surface-plasmon resonance frequency [47, 51]. This frequency is given by the following formula [40]:

$$
\omega_{\mathrm{s}}=\frac{\omega_{\mathrm{P}}}{\sqrt{\frac{2+\mathrm{f}}{1-\mathrm{f}} \varepsilon_{\mathrm{m}}+\varepsilon_{1}^{\text {core }}\left(\omega_{\mathrm{s}}\right)}}
$$

The medium dielectric function $\varepsilon_{\mathrm{m}}$ is taken as a constant number of 3.1 for the $\mathrm{Al}_{2} \mathrm{O}_{3}$ matrix in the energy range examined. Therefore, the above equation suggests that three factors will affect the surface-plasmon frequency:

$\boldsymbol{\omega}_{\boldsymbol{P}}$, the plasma frequency $w_{p}=\left(n e^{2} / \varepsilon_{0} m_{e f f}\right)^{2}$ depends upon the electron density $n$ and effective mass $m_{e f f}$.

$\varepsilon_{1}^{\text {core }}\left(\omega_{s}\right)$, the core electrons contribution to the dielectric constant in the vicinity of the surface-plasmon resonance. $f$, the volume concentration of the metal.

Initially, we discuss the lattice constant effect on $\omega_{\mathrm{p}}$. We follow the work of Cai et al [52], who noted that due to strain, the plasma frequency $\omega_{\mathrm{P}}$ in Eq. 6 changes due to the resulting change in free electron density, the plasma frequency can be written for Face-Centered Cubic(FCC) metals as [40] :

$$
\omega_{P}(a)=\omega_{P}(\infty) \cdot\left(1-\frac{3}{2} \frac{\Delta a}{a_{0}}\right)
$$

where $\omega_{P}(a)$ and $\omega_{P}(\infty)$ are the plasma frequency for AuNPs and the bulk, respectively. We note that $a_{0}=4.08 \AA$ is the lattice constant of the bulk gold. Clearly, any variation in the lattice constant $a$ due to mechanical strain will impact the plasma frequency $\omega_{P}(a)$, which will result in either a blue or redshift of the optical spectra. The difference between the deformed and undeformed lattice parameter is denoted $\Delta a$. Fig. 8 presents the variation of the volume plasmon as a function of annealing temperature. The value of $\omega_{P}$ increases firstly for the A1 series from $1.36 \times 10^{16} \mathrm{~Hz}$ to $1.4 \times 10^{16} \mathrm{~Hz}$ and decreases secondly for the A2 series from $1.39 \times 10^{16} \mathrm{~Hz}$ to $1.36 \times 10^{16} \mathrm{~Hz}$ when the annealing temperature increases from $25^{\circ} \mathrm{C}$ to $500{ }^{\circ} \mathrm{C}$. The increasing of $\omega_{P}$ leads to a blue-shift while its decrease leads to a red-shift according to Eq. 6 .

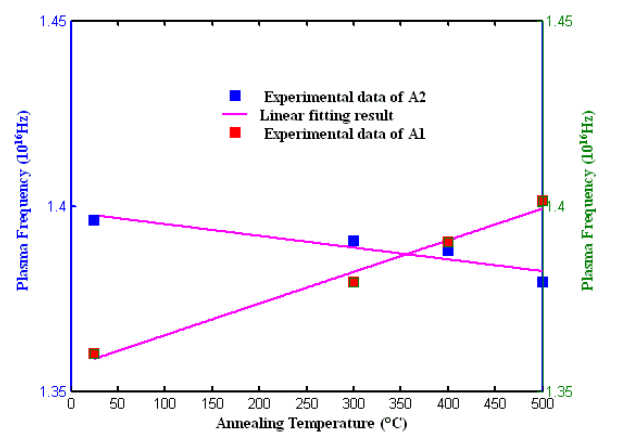

Fig. 8 Variation of plasma frequency of Au-NPs with annealing temperatures

Furthermore, any strain-induced change in lattice constant $a$ also impacts the Fermi velocity $v_{F}$ which can be written as:

$$
v_{F}(R)=v_{F 0}\left(1-\frac{\Delta a}{a_{0}}\right)
$$

where $v_{F 0}$ is the corresponding value of the bulk. We can now focus on the contribution from $\varepsilon_{1}^{\text {core }}\left(\omega_{s}\right)$, after eliminating the contribution from $\omega_{P}(a)$. It is known that the core electrons have important influences on 
the SPR energy of the noble-metal particles when considering the screening effect from the $d$ electrons. As discussed by Lerme et al. [53], mechanical strain affects also the dielectric function for the ionic core, or bound electrons. This can be written as:

$$
\varepsilon^{\text {core }}(\omega, a)=\frac{\varepsilon^{\text {core }}(\omega)+2+2 v\left(\varepsilon^{\text {core }}(\omega)-1\right)}{\varepsilon^{\text {core }}(\omega)+2-v\left(\varepsilon^{\text {core }}(\omega)-1\right)}
$$

The bulk value of $\mathrm{Au} \boldsymbol{\varepsilon}_{1}^{\text {core }}$ in the vicinity of $\boldsymbol{\omega}_{\boldsymbol{s}}$ is $\approx 10$ [35], $v$ captures the strain-induced change in lattice constant as:

$$
v=\left(\frac{a_{0}}{a}\right)^{3}
$$

We therefore plot in Figs. 9-12 the contribution of the ionic core to the real and imaginary parts of the dielectric function for our samples subject to both tensile and compressive strain. The figure clearly shows that the core dielectric function $\varepsilon^{\text {core }}$ is substantially impacted by strain.

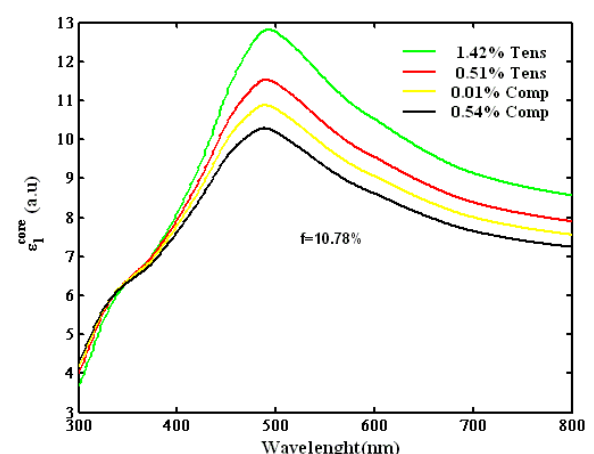

Fig. 9 Plot of real part of the core dielectric function $\varepsilon_{1}^{c o r e}$ of the series A1 as a function of strain

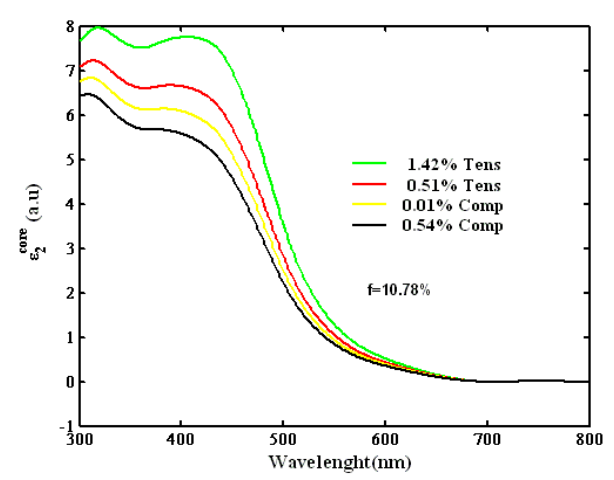

Fig. 10 Plot of imaginary part of the core dielectric function $\varepsilon_{2}^{\text {core }}$ of the series A1 as a function of strain

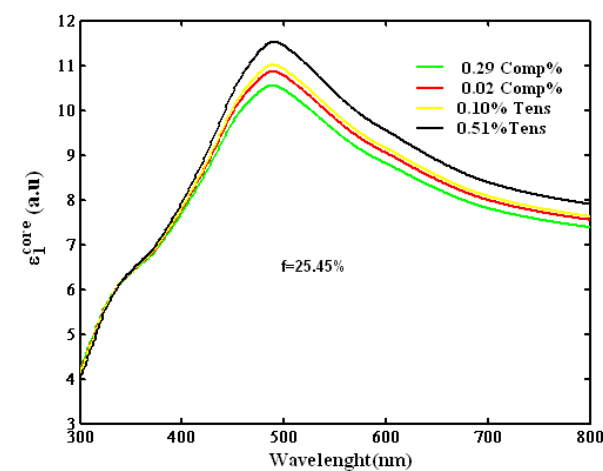

Fig. 11 Plot of real part of the core dielectric function $\varepsilon_{1}^{\text {core }}$ of the series A2 as a function of strain

As seen in Fig. 9, $\varepsilon_{1}^{\text {core }}$ decreases from about 12.82 to 10.28 for the $\mathrm{A} 1$ series and increases from about 10.55 to 11.52 for the A2 series, when the annealing temperatures increases from $25^{\circ} \mathrm{C}$ to $500^{\circ} \mathrm{C}$ as shown in Fig. 11 . The imaginary part $\varepsilon_{2}^{\text {core }}$ of the core dielectric function reported in Fig. 10 and Fig. 12, shows a significant enhancement due to strain .Therefore, an increase in the imaginary part of the dielectric function, which represents an enhancement in the active damping mechanisms, is known to strongly reduce the magnitude of the far field optical efficiency [54, 55], this explains the reduced scattering and absorption efficiencies due to strain. https://doi.org/10.30799/jtfr.006.17010101

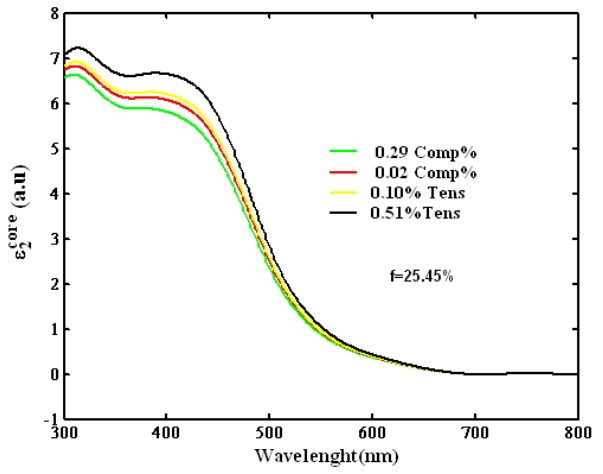

Fig. 12 Plot of imaginary part of the core dielectric function $\varepsilon_{2}^{\text {core }}$ of the series A2 as a function of strain

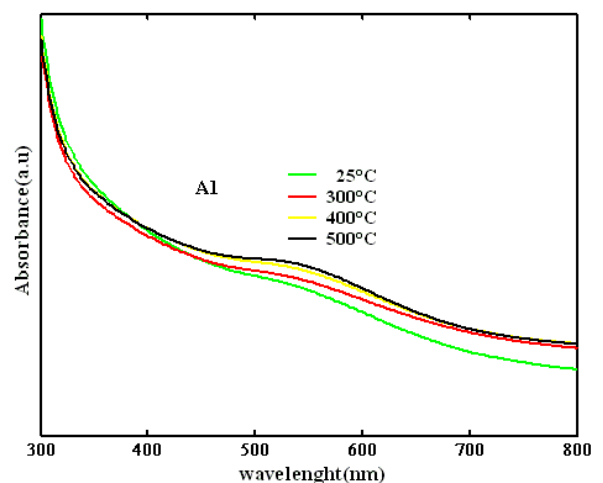

Fig. 13 Optical absorption spectra of the series A1 at different annealing temperatures

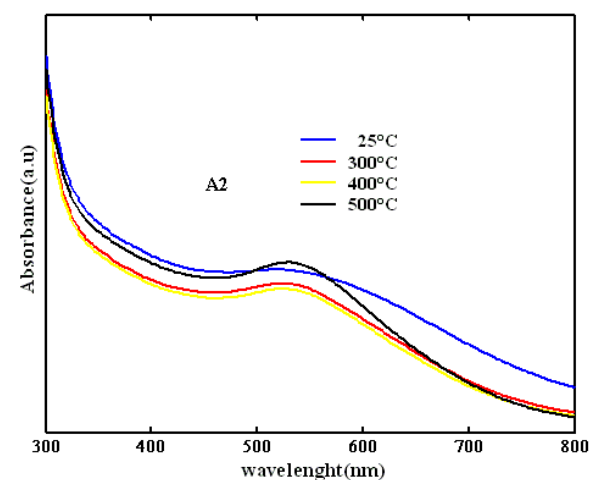

Fig. 14 Optical absorption spectra of the series A2 at different annealing temperatures

The optical absorption spectra as a function of annealing temperature for the two series A1 and A2 are shown in Figs. 13-14. From Fig. 13, we can see that the sample which was not thermally annealed, the SPR peak characteristic of the gold particles is not discernable. The broad absorption peak in the unannealed sample can be associated to the gold particle sizes smaller than $2 \mathrm{~nm}$ [56]. With the increase of annealing temperature, a progressive of a broad band appears. From the measured absorption spectra, it is not easy to determine the position of the SPR band and describe the trend of SPR bands in the sample because the band is weak and broad. Unlike in the A1series, a remarkable SPR peak is observed for the as-deposited sample in series A2 as seen in Fig. 14. This means that the intensity of SPR absorption band is correlated with the change in the volume fraction of Au nanoparticles [5, 35, 36].The intensity of the SPR absorption band increased progressively with the increase of the annealing temperature of the films. This effect is attributed to the increment in the particle size caused as mentioned above by the increase of the annealing temperature of the samples, since the SPR absorption of small metal particles is originated from the collective motion of the conduction electrons interacted with external electromagnetic field of the incident radiation. Using M-G theory with mean free path correction, the theoretical absorption spectra were calculated by a combination of Eqs. (1-3) and (6-9). The used values of plasma frequency, Fermi velocity, damping constant and the scattering parameter, $\omega_{p}, v_{F}, \Gamma, \mathrm{A}$, respectively were cited in the work [28, 41, 42, 48]. The simulation and the experimental plots are shown in Figs. 15-16. The parameter values deducted from this simulation are summarized in Table 3 . 
Table 3 Plasmon peak, average size of two series A1 and A2 annealed at different temperatures

\begin{tabular}{llll}
\hline Sapmle Number & $\begin{array}{l}\text { Annealing } \\
\text { temperature }\left({ }^{\circ} \mathrm{C}\right)\end{array}$ & $\lambda_{\max }(\mathrm{nm})$ & Particle Size $(\mathrm{nm})$ \\
\hline $\mathrm{A} 1$ & as- prepared & 499 & 1.91 \\
& $300^{\circ} \mathrm{C}$ & 501 & 2.10 \\
& $400^{\circ} \mathrm{C}$ & 502 & 2.30 \\
& $500^{\circ} \mathrm{C}$ & 503 & 2.40 \\
\hline $\mathrm{A} 2$ & as- prepared & 515 & 2.50 \\
& $300^{\circ} \mathrm{C}$ & 520 & 2.80 \\
& $400^{\circ} \mathrm{C}$ & 526 & 3.30 \\
& $500^{\circ} \mathrm{C}$ & 530 & 3.70 \\
\hline
\end{tabular}

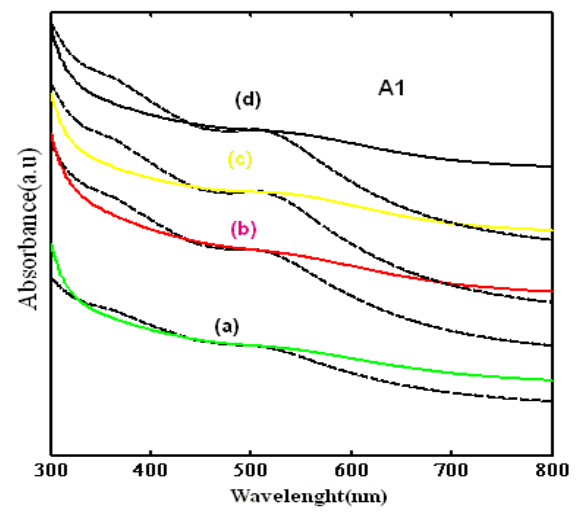

Fig. 15 Experimental and M-G simulated optical absorption spectra for the series A1 as deposited (a) and annealed at (b) $300^{\circ} \mathrm{C}$, (b) $400{ }^{\circ} \mathrm{C}$ and (d) $500^{\circ} \mathrm{C}$

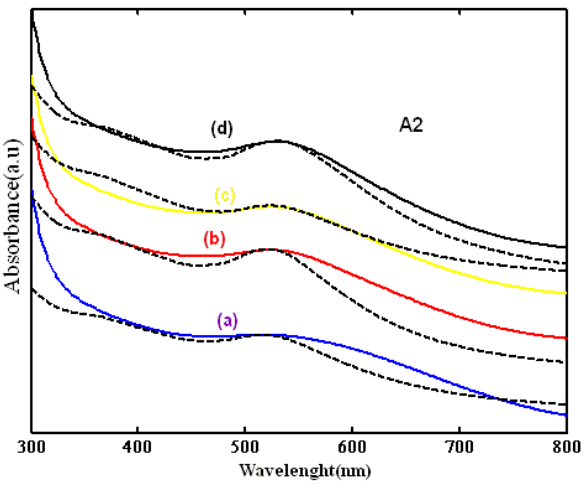

Fig. 16 Experimental and M-G simulated optical absorption spectra for the series A2 as deposited (a) and annealed at (b) $300^{\circ} \mathrm{C}$, (b) $400{ }^{\circ} \mathrm{C}$ and (d) $500^{\circ} \mathrm{C}$

The size effect on the SPR band has two stages. The first stage is of Au particles smaller than $2 \mathrm{~nm}$. The second stage is of Au particles beyond 2 $\mathrm{nm}$. At the first stage, the intensity of the SPR band increases slightly, the plasmon peak positions just vary from $501 \mathrm{~nm}$ to $503 \mathrm{~nm}$, and the obtained average sizes increase slightly from $2.1 \mathrm{~nm}$ to $2.4 \mathrm{~nm}$ when heating temperature varies from 300 to $500{ }^{\circ} \mathrm{C}$. The size effect on the SPR band shift can be ignored. This results are consistent with the reported value for $\mathrm{Au}-\mathrm{Nps}$, where SPR appears around $500 \mathrm{~nm}$ [57-60]. Similar observations have been reported for other gold-dispersed dielectric materials: Alvarez et al [56] prepared passivated gold particles with sizes in the range 1.4-3.2 $\mathrm{nm}$, found that with decreasing size, the SPR band broadened until it became unidentifiable for sizes less than $2 \mathrm{~nm}$. Palpant et al [35] found also, that the plasmon absorption is damped and blueshifted with decreasing particle size, in the case of gold clusters in the size range 2-4 $\mathrm{nm}$, embedded in alumina matrix grown by co-deposition technique using pulsed laser ablation. Formation of gold nanoparticles embedded in silica films using RF-magnetron sputtering technique with subsequent thermal treatment have been reported in [48]. In the second stage, the intensity of the SPR band continuously increases while the SPR band shifts to a longer wavelength with increasing the size of Au particles. The plasmon peak positions vary from $515 \mathrm{~nm}$ to $530 \mathrm{~nm}$, and the obtained average sizes from the optical absorption spectra, increase from $2.5 \mathrm{~nm}$ to $3.70 \mathrm{~nm}$, when heating temperature varies from 25 to $500^{\circ} \mathrm{C}$.

According to our simulation results, the shift of the SPR band towards shorter wavelength may be ascribed to the decrease of the volume fraction of Au-NPs. The increasing of the intensity of the peak absorption band with increasing annealing temperature can be attributed to the increase of size of Au particles. The heat treatment has a remarkable effect on the A2 series with high $\mathrm{Au}$ concentration while this effect is negligible for the A1 series.

\section{Conclusion}

In this work, we have investigated the effect of concentration and thermal annealing on the structural and optical absorption spectra of gold/alumina nanocomposite films synthesized by RF-sputtering technique. Gold volume fraction in the composite films was fixed by argon pressure deposition. It was found that the structural and the optical properties of the samples were strongly improved by volume fraction of Au particles and thermal annealing. No diffraction peaks corresponding to the gold phase were detected in the as deposited samples for the lower concentration. Increase in the gold fill fraction in the samples give rise to a broad peaks characteristic of gold nanoparticles in the diffractograms. From the SPR absorption band of the as deposited samples, it can be assumed that the Au was incorporated in the form of very small nanoparticles. After annealing, the samples with higher Au contents favored the growth of gold nanoparticles and have a great impact on the intensity, size and the shift of the plasmon peak.

\section{Acknowledgments}

We are grateful to Professor M.J.M. Gomes from the Centre of Physics, University of Minho, Portugal, or the experiments. A. Chouiyakh would like to thank the National Center for Scientific and Technical Research (CNRST) of Morocco for EDX measurements.

\section{References}

[1] U. Kreibig, M. Vollmer, Optical properties of metal clusters, Springer, Berlin 1995

[2] C.F. Bohren, D.R. Huffman, Absorption and scattering of light by small particles, John Wiley, New York, 1983.

[3] K.L. Kelly, E. Coronado, L.L. Zhao, G.C. Schatz, The optical properties of metal nanoparticles: the influence of size, shape, and dielectric environment, J. Phys. Chem. B. 107 (2003) 668-677.

[4] U. Kreibig, C.V .Fragstein, The limitation of electron mean free path in small silver particles, Z. Phys. 224 (1969) 307-323.

[5] U. Kreibig, L. Genzel, Optical absorption of small metallic particles, Surf. Sci. 156 (1985) 678-700

[6] C. Noguez, Surface plasmons on metal nanoparticles: the influence of shape and physical environment, J. Phys. Chem. C. 111 (2007) 3806-3819.

[7] S. Link, M.A. El-Sayed, Shape and size dependence of radioactive, non radioactive and photo thermal properties of gold nanocrystals, Int. Rev. Phys. Chem. 19 (2000) 409-453.

[8] F.K. Alanazi, A.A. Radwan, I.A. Alsarra, Biopharmaceutical applications of nanogold, Saudi Pharm. J. 18 (2010) 179-193.

[9] I.N. Remediakis, N. Lopez, J.K. Nørskov, CO oxidation on gold nanoparticles: theoretical studies, Appl. Catal. A Gen. 291 (2005) 13-20.

[10] M. Haruta, Nanoparticulate gold catalysts for low-temperature CO oxidation, J. New Mater. Electrochem. Syst. 7 (2004) 163-172.

[11] Y. Tai, J. Murakami, K. Tajiri, F. Ohashi, M. Daté, S. Tsubota, Oxidation of carbon monoxide on Au nanoparticles in titania and titania-coated silicaaerogels, Appl. Catal. A Gen. 268 (2004) 183-187.

[12] K. Mallick, M.S. Scurrell, CO oxidation over gold nanoparticles supported on TiO 2 and $\mathrm{TiO}$ 2-ZnO: catalytic activity effects due to surfacemodification of $\mathrm{TiO}_{2}$ with ZnO, Appl. Catal. A Gen. 253 (2003) 527-536.

[13] M. Shakibaie, H. Forootanfar, K. Mollazadeh-Moghaddam, Z. Bagherzadeh, N. Nafissi-Varcheh, A.R. Shahverdi, M.A. Faramarzi, Green synthesis of gold nanoparticles by the marine microalga Tetraselmis suecica, Biotechnol. Appl. Biochem. 57 (2010) 71-75.

[14] C.M. Shih, Y.T. Shieh, Y.K. Twu, Preparation of gold nanopowders and nanoparticles using chitosan suspensions, Carbohydr. Polym. 78 (2009) 309315.

[15] K. Kalishwaralal, V. Deepak, S.R.K. Pandian, S. Gurunathan, Biological synthesis of gold nanocubes from Bacillus licheniformis, Bioresour. Technol. 100 (2009) 5356-5358.

[16] H. Wei, X. Zhang, C. Cheng, S.X. Cheng, R.X. Zhuo, Self-assembled, thermosensitive micelles of a star block copolymer based on PMMA and PNIPAA for controlled drug delivery, Biomaterials 28 (2007) 99-107.

[17] V.P. Torchilin, Multifunctional nanocarriers, Adv. Drug Deliv. Rev. 64 (2012) 302-315.

[18] G. Han, P. Ghosh, M. De, V.M. Rotello, Drug and gene delivery using gold nanoparticles, Nanobiotechnol. 3 (2007) 40-45.

[19] M.T. Castaneda, A. Merkoci, M. Pumera, S. Alegret, Electrochemical genosensors for biomedical applications based on gold nanoparticles, Biosens. Bioelectron. 22 (2007) 1961-1967.

[20] K. Aslan, J.R. Lakowicz, C.D. Geddes, Tunable plasmonic glucose sensing based on the dissociation of Con A-aggregated dextran-coated gold colloids, Anal. Chim. Acta 517 (2004) 139-144.

[21] X. Huang, P.K. Jain, I.H. El-Sayed, M.A. El-Sayed, Gold nanoparticles: interesting optical properties and recent applications in cancer diagnostics and therapy, Nanomedicine 2 (2007) 681-693.

[22] M. Kubo, S. Nakamura, The dielectric constant of dispersion of spherical particles, Bull. Chem. Soc. Jpn., 26(6) (1953) 318-322. 
[23] T. Maniv, H. Metiu, Electrodynamics at a metal surface with applications to the spectroscopy of adsorbed molecules. I. General theory, Phys. Rev. B, 22(10) (1980) 4731-4738

[24] J.C. Maxwell-Garnett, Colours in metal glasses and in metallic films, Philos. Trans. R. Soc. London. 203 (1904) 385-420.

[25] V.M. Shalaev, Optical properties of nanostructured random media, Topics in Applied Physics, Vol. 82, Springer, Berlin, 2002.

[26] E.D. Palik, Handbook of optical constants of solids, Academic Press, New York, 1991.

[27] H. Hovel, S. Fritz, A. Hilger, U. Kreibig, M. Vollmer, Width of cluster plasmon resonances: bulk dielectric functions and chemical interface damping, Phy. Rev. B. 48 (1993) 18178-18188.

[28] A. Belahmar, A. Chouiyakh, Investigation of surface plasmon resonance and optical band gap energy in gold/silica composite films prepared by RFsputtering, J. Nanosci. Tech. 2(2) (2016) 81-84.

[29] D. Dhara, B. Sundaravel, T.R. Ravindran, K.G.M. Nair, C. David. B.K. Panigrahi, et al, Spill out effect in gold nanoclusters embedded in $\mathrm{c}-\mathrm{Al}_{2} \mathrm{O}_{3}$ (0001) matrix, Chem. Phys. Lett. 399 (2004) 354-358.

[30] M. Ohkubo, N. Susuki, Morphology of small gold crystals formed inside sapphire by ion implantation, Philos. Mag. Lett. 57 (1988) 261-265.

[31] D.O. Henderson, R. Mu, Y.S. Tung, M.A. George, A. Burger, S.H. Morgan, et al, Atomic force microscopy of Au implanted in sapphire, J. Vac. Sci. Technol. B 13 (1995) 1198-1202.

[32] Y. Hosoya, T. Suga, T. Yanagawa, Y. Kurokawa, Linear and nonlinear optical properties of sol-gel-derived Au nanometer-particle-doped alumina, J. Appl. Phys. 81 (1997) 1475-1480.

[33] S. Muto, T. Kubo, Y. Kurokawa, K. Suzuki, Third-order nonlinear optical properties of Disperse Red 1 and Au nanometer-size particle-doped alumina films prepared by the sol-gel method, Thin Sol. Films 322 (1998) 233-237.

[34] J. Lermé, B. Palpant, B. Prével, E. Cottancin, M. Pellarin, M. Treilleux, et al, Optical properties of gold metal clusters: A time-dependent local-densityapproximation investigation, Eur. Phys. J. 4 (1998) 95-108.

[35] B. Palpant, B. Prével, J. Lermé, E. Cottancin, M. Pellarin, M. Treilleux, et al, Optical properties of gold clusters in the size range 2-4 nm, Phys. Rev. B 57 (1998) 1963-1970.

[36] E. Cottancin, J. Lermé, M. Gaudry, M. Pellarin, J.L. Vialle, M. Broyer, et al, Size effects in the optical properties of Au n Ag n embedded clusters, Phys. Rev. B 62 (2000) 5179-5185.

[37] M. Gaudry, J. Lermé, E. Cottancin, M. Pellarin, J.L. Vialle, M. Broyer, et al, Optical properties of $\left(\mathrm{Au}_{\mathrm{x}} \mathrm{Ag}_{1-\mathrm{x}}\right)(\mathrm{n})$ clusters embedded in alumina: Evolution with size and stoichiometry, Phys. Rev. B 6408 (2001) 5407-5413.

[38] J. Garcia-Serrano, U. Pal, Synthesis and characterization of Au nanoparticles in $\mathrm{Al}_{2} \mathrm{O}_{3}$ matrix, Int. J. Hyd. Energy 82 (2003) 637-640.

[39] H.B. Liao, R.F. Xiao, J.S, Fu, G.K.L. Wong, Large third-order nonlinear optical susceptibility of $\mathrm{Au}-\mathrm{Al}_{2} \mathrm{O}_{3}$ composite films near the resonant frequency, Appl. Phys. B 65 (1997) 673-676.

[40] J. Wang, W.M. Lau, Q. Li, Effects of particle size and spacing on the optical properties of gold nanocrystals in alumina, J. Appl. Phys. 97 (2005) 114303114310.

[41] A. Belahmar, A. Chouiyakh, Influence of the fabrication conditions on the formation and properties of gold nanoparticles in alumina matrix produced by co-sputtering, Int. J. Nano. Mater. Sci. 3 (2014) 16-29.

[42] A. Belahmar, A. Chouiyakh, Sputtering synthesis and thermal annealing effect on gold nanoparticles in $\mathrm{Al}_{2} \mathrm{O}_{3}$ matrix, J. Nanosci. Tech. 2(2) (2016) 100-103.
[43] A. Belahmar, A. Chouiyakh, Structural and optical study of Au nanoparticles incorporated in $\mathrm{Al}_{2} \mathrm{O}_{3}$ and $\mathrm{SiO}_{2}$ thin films grown by RF-sputtering, Int. J. Adv. Res. Comput. Sci. Softw. Eng. 6 (2016) 109-116.

[44] G.Q. Yu, B.K. Tay, Z.W. Zhao, X.W. Sun, Y.Q. Fu, Ion beam co-sputtering deposition of $\mathrm{Au} / \mathrm{SiO}_{2}$ nanocomposites, Phys. E. Low-dim. Sys. Nanostr. 27 (2005) 362-368.

[45] L. Armelao, D. Barreca, G. Bottaro, G. Bruno, A. Gasparotto, M. Losurdo, E. Tondello, RF-sputtering of gold on silica surfaces: Evolution from clusters to continuous films, Mater. Sci. Eng. C 25 (2005) 599-603.

[46] D. Dalacu, L. Martinu, Spectroellipsometric characterization of plasmadeposited $\mathrm{Au} / \mathrm{SiO}_{2}$ nanocomposite films, J. Appl. Phys. 87 (2000) 228-235.

[47] L. Genzel, T.P. Martin, Infrared absorption by surface phonons and surface plasmons in small crystals, Surf. Sci.34 (1973) 33-49.

[48] A. Belahmar, A. Chouiyakh, Effect of post-annealing on structural and optical properties of gold nanoparticles embedded in silica films grown by RFsputtering, Adv. Phys. Theory. Appl. 15 (2003) 38-46.

[49] A. Belahmar, A. Chouiyakh, Influence of argon pressure on the optical bandgap energy and urbach tail of sputtered $\mathrm{Au} / \mathrm{SiO}_{2}$ nanocomposite films, Int. J. Adv. Res. Comput. Sci. Softw. Eng. 6 (2016) 7-13.

[50] M. Torrell, R. Kabir, L. Cunha, M.I. Vasilevskiy, F. Vaz, A. Cavaleiro, E. Alves, N.P. Barradas, Tuning of the surface plasmon resonance in $\mathrm{TiO}_{2} / \mathrm{Au}$ thin films grown by magnetron sputtering: The effect of thermal annealing, J. Appl. Phy. 109 (2011) 074310-074318.

[51] S.K. Mandal, R.K. Roy, A.K. Pal, Surface plasmon resonance in nanocrystalline silver particles embedded in $\mathrm{SiO}_{2}$ matrix, J. Phys. D: Appl. Phys. 35 (2002) 2198-2205.

[52] W. Cai, H. Hofmeister, M. Dubiel, Importance of lattice contraction in surface plasmon resonance shift for free and embedded silver particles, Eur.Phys. J. D 13 (2001) 245-253.

[53] J. Lerme, M. Pellarin, M.E. Cottancin, M. Gaudry, M. Broyer, N.D. Fatti, F. Vallee, C. Voisin, Influence of lattice contraction on the optical properties and the electron dynamics in silver clusters, Eur. Phys. J. D 17 (2001) 213-220.

[54] E.A. Coronado, G.C. Schatz, Surface plasmon broadening for arbitrary shape nanoparticles: A geometrical probability approach, J. Chem. Phys. 119 (2003) 3926-3934.

[55] K.S, Lee, M.A. El-Sayed, Gold and silver nanoparticles in sensing and imaging: sensitivity of plasmon response to size, shape, and metal composition, J. Chem. Phys. B 110 (2006)19220-19225.

[56] M.M. Alvarez, J.T. Khoury, T.G. Schaaff, M.N. Shafigullin, I. Vezmar, R.L. Whetten Optical absorption spectra of nanocrystal gold molecules, J. Phys. Chem. B. 101 (1997) 3706-3712.

[57] D.G. Duff, A. Baiker, P.P. Edwards, A new hydrosol of gold clusters, 1. Formation and particle size variation, Langmuir 9 (1993) 2301-2309.

[58] N. Pincon, B. Palpant, D. Prot, E. Charron, S. Debrus, Third-order nonlinear optical response of $\mathrm{Au}: \mathrm{SiO}_{2}$ thin films: Influence of gold nanoparticle concentration and morphologic parameters, The Eur. Phy. J. D 19 (2002) 395402.

[59] N.P. Roetzinger, D. Prot, B. Palpant, E. Charron, S. Debrus, Large optical Kerr effect in matrix-embedded metal nanoparticles, Mat. Sci. Eng. C 19 (2002) 5154.

[60] J. Lerme, B. Palpant, B. Prevel, E. Cottancin, M. Pellarin, M. Treilleux, J.L. Vaille, A. Perez, M. Broyer, Optical properties of gold metal clusters: A time-dependent local-density-approximation investigation, The Eur. Phys. J. D 4 (1998) 95-108. 